\title{
How to organize a fairly large vowel inventory: the vowels of Fering (North Frisian)
}

\author{
Ocke-Schwen Bohn \\ Department of English, Aarhus Universitet \\ engosb@hum.au.dk
}

This paper presents parts of the results of the first stage in the phonetic documentation of Fering, a dialect of North Frisian. Descriptions of Fering indicate that it has a large vowel inventory (15 monophthongs, 7 diphthongs, and 3 triphthongs). Ten older male native speakers were recorded, producing the vowel and consonant inventory at different speaking rates, in different phonetic contexts, and in different speaking styles. The results of the acoustic analyses of the vowels of Fering throw light on the questions of a) how the vowel space is exploited in Fering, b) how Fering differentiates its large vowel inventory, c) to what extent consonant-vowel coarticulation affects the acoustic differentiation of vowel categories, and d) to what extent the implementation of the long-short vowel contrasts is affected by speaking rate. The results also provide a more accurate description of the vowel system of an endangered language than do previous auditory accounts.

\section{Introduction}

Fering is a dialect of the West Germanic language North Frisian. Of the three Frisian languages, West Frisian (ca. 400,000 speakers in the northwest Netherlands) is least endangered, East Frisian (less than 200 speakers in three villages in Lower Saxony) is moribund, and North Frisian (ca. 7,000 speakers) is acutely endangered. North Frisian itself consists of several mutually unintelligible dialects, the most important division being between Mainland North Frisian (with at least five dialects), spoken in the extreme northwest of the mainland of the German state Schleswig-Holstein, and Island North Frisian spoken on the North Sea islands Sylt, Föhr, Amrum, and Heligoland. Of these, only the dialects spoken on Föhr (Fering) and the neighboring island Amrum (Öömrang) are mutually intelligible.

All dialects of North Frisian are acutely endangered: there are no adult monolingual speakers of any dialect - many speakers are fluent in three or more languages - and the number of speakers of the dialects of North Frisian ranges between less than 100 and ca. 2000. It appears that Fering stands strongest among the North Frisian dialects. It has the largest number of native speakers (1500 on the island plus an unknown number of emigrants 
Table 1 The phoneme inventory of Fering.

\begin{tabular}{|c|c|c|}
\hline \multicolumn{2}{|c|}{ Vowels } & Consonants \\
\hline \multicolumn{2}{|c|}{15 stressed monophthongs (plus unstressed /a/): } & Maximally 29 consonants: \\
\hline 7 short vowels: & 8 long vowels: & $\begin{array}{lllll}p & t & t & t^{j} & k\end{array}$ \\
\hline I Y U & i: y: u: & $\begin{array}{lllll}b & d & d & d^{j} & g\end{array}$ \\
\hline$\varepsilon œ っ$ & $\begin{array}{c}\text { e: } \phi: \text { o: } \\
\varepsilon:\end{array}$ & 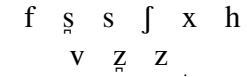 \\
\hline 7 & $\mathrm{~b}:$ & 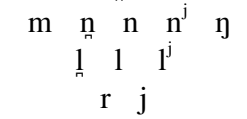 \\
\hline \multicolumn{3}{|c|}{$\begin{array}{l}7 \text { diphthongs: } \\
\varepsilon i, \text { ui, au, ia, ua, pi, } \varnothing \mathbf{i}\end{array}$} \\
\hline \multicolumn{2}{|c|}{3 triphthongs: } & \\
\hline
\end{tabular}

mostly in New York and Northern California), and it differs from most other dialects in that it is used not just at home but also publicly, especially in the Western part of the island (Westerland Föhr with the Weesdring dialect of Fering). The Westerland Föhr villages of Taftem, Olersem, and Söleraanj (German: Toftum, Oldsum, Süderende) are considered a stronghold of Fering, and the variety of Fering spoken in these villages is reasonably homogenous. It is the form of Fering as spoken in these villages that is the focus of this study.

Table 1 summarizes the phoneme inventory of Fering as presented in dictionaries (Arfsten 1965, Wilts et al. 1986), a self-guided language course (Sjölin et al. 1985), and a recent handbook chapter (Walker \& Wilts 2001).

Walker \& Wilts (2001) mention that the consonants with dental place of articulation have merged with their alveolar counterparts in the post-war generation. Arfsten (1965) and Wilts et al. (1986) emphasize that $/ \mathrm{t}^{\mathrm{j}}, \mathrm{d}^{\mathrm{j}}, \mathrm{n}^{\mathrm{j}}, \mathrm{l}^{\mathrm{j}} /$ are not consonant clusters but rather consonants with a postalveolar/palatal place of articulation and a / j/-like offglide.

The purpose of the project which provided the data on which the present study is based is twofold. First, the project provides an acoustic documentation of the vowels and consonants of Fering. As is customary in dialectological and sociolinguistic studies which aim to document conservative and/or endangered speech forms, the speaker group in the first stage of the documentation consisted of older male speakers of Fering. Consultations of dictionaries, textbooks, and native Fering informants led to the construction of word and sentence lists, which were used to elicit the segmental inventory of Fering in different phonetic contexts (for vowels and consonants), at two speaking rates (for selected vowels), and in two speaking styles (for selected consonants). Additionally, the talkers were recorded reading the fable 'The North Wind and the Sun' and the first 100 items from the Swadesh word list. (The complete corpus is available on CD-ROM from the author to any interested party.)

Second, the fairly comprehensive acoustic documentation of the sounds of Fering is used as a database to address questions of general interest in phonetic typology. With respect to the vowels of Fering (which are the focus of this paper), the general questions that will be addressed concern how Fering vowels are distributed in the acoustic vowel space, how a language with a large vowel inventory like Fering differentiates vowels that are close in the F1/F2 space, to what extent consonant-vowel coarticulation affects the acoustic differentiation of vowel categories, and to what extent the implementation of the long-short vowel contrasts is affected by speaking rate. 


\section{Methods}

\subsection{Subjects}

Ten male native speakers of Fering participated as unpaid volunteers. The speakers, who were recruited through local contacts, met the following selection criteria: native speaker of the Weesdring dialect of Fering (villages Taftem, Olersem, Söleraanj), aged between 70 and 80 years, no severe hearing loss (according to self-report), and predominant use of Fering (as established through a language background questionnaire). The language background questionnaire ascertained that all talkers used Fering more than other languages, had Feringspeaking spouses and spoke Fering with their children and grandchildren. The mean age of the talkers was 74.7 years $(\mathrm{SD}=1.8)$ at the time of the recordings. As expected, all speakers were fluent in at least two additional languages (i.e. High German, Low German, American English, and/or Danish).

\subsection{Materials and procedure}

The talkers were recorded reading (among other material):

(i) the complete set of Fering vowels in $/ \mathrm{hVt} /$ and $/ \mathrm{dVt} /$ syllables in citation form,

(ii) selected vowels in real Fering words both in citation form and in sentence context, and

(iii) lists of real Fering words containing the consonants of Fering in various contexts and positions.

The $/ \mathrm{hVt} /$ and $/ \mathrm{dVt} /$ syllables were produced in two blocks of 29 utterances, in each of which the 25 vowels occurred in random order. (The first two and the final two utterances contained filler items that were not analyzed.) Because most of the $/ \mathrm{hVt} /$ and $/ \mathrm{dVt} / \mathrm{syllables}$ are not real Fering words, and because letter-sound correspondences of the primary literary language, High German, might affect the production of the target syllables, production of Fering $/ \mathrm{hVt} /$ and $/ \mathrm{dVt} /$ syllables was cued by having the talkers read (aloud) real rhyming words immediately preceding the production of the target syllable. For instance, production of the nonword heet was cued by having the subject read sweet 'sweat', feet 'fat', leet 'let', heet.

The real Fering words in citation form and in sentence context were also each produced in two randomized blocks. The sentence context was $I k$ sai $X t u d i$ 'I say X to you'. The word list that targeted consonants elicited one token per word. The items in each of the lists were preceded by identification numbers, which the talkers read in Fering.

Recordings were made in a quiet room on a Sony DAT recorder (model TCD-D8) with a Sony electret condenser microphone (model ECM-959A). The recorded material was later digitized on a standard PC. Tokens targeting the vowels of Fering were digitized at a $11.025 \mathrm{kHz}$ sampling rate with 16 -bit resolution after low-pass filtering at $5.0 \mathrm{kHz}$.

\subsection{Acoustic analyses}

Vowel durations were measured using a waveform editing program (COOL EDIT, Syntrillium Co.). Vowel duration was defined as the interval from the first zero crossing in the periodic portion of the signal to the last zero crossing before cessation (or sudden decrease in amplitude) of periodicity.

The frequencies of the first three formants were estimated using the LPC algorithm of a speech analysis program (SpeechStation 2, Sensimetrics Co.) by placing a 128 point Hamming window over three points in the vowel portion: a point $25 \%$ through the vocalic portion, the vowel center at $50 \%$ of the vowel duration, and a point at $75 \%$ of the vowel duration. The default LPC order was 12. Missing information due to merged formants or other obvious peak picking errors was supplied by successively increasing the LPC order by 2 . 


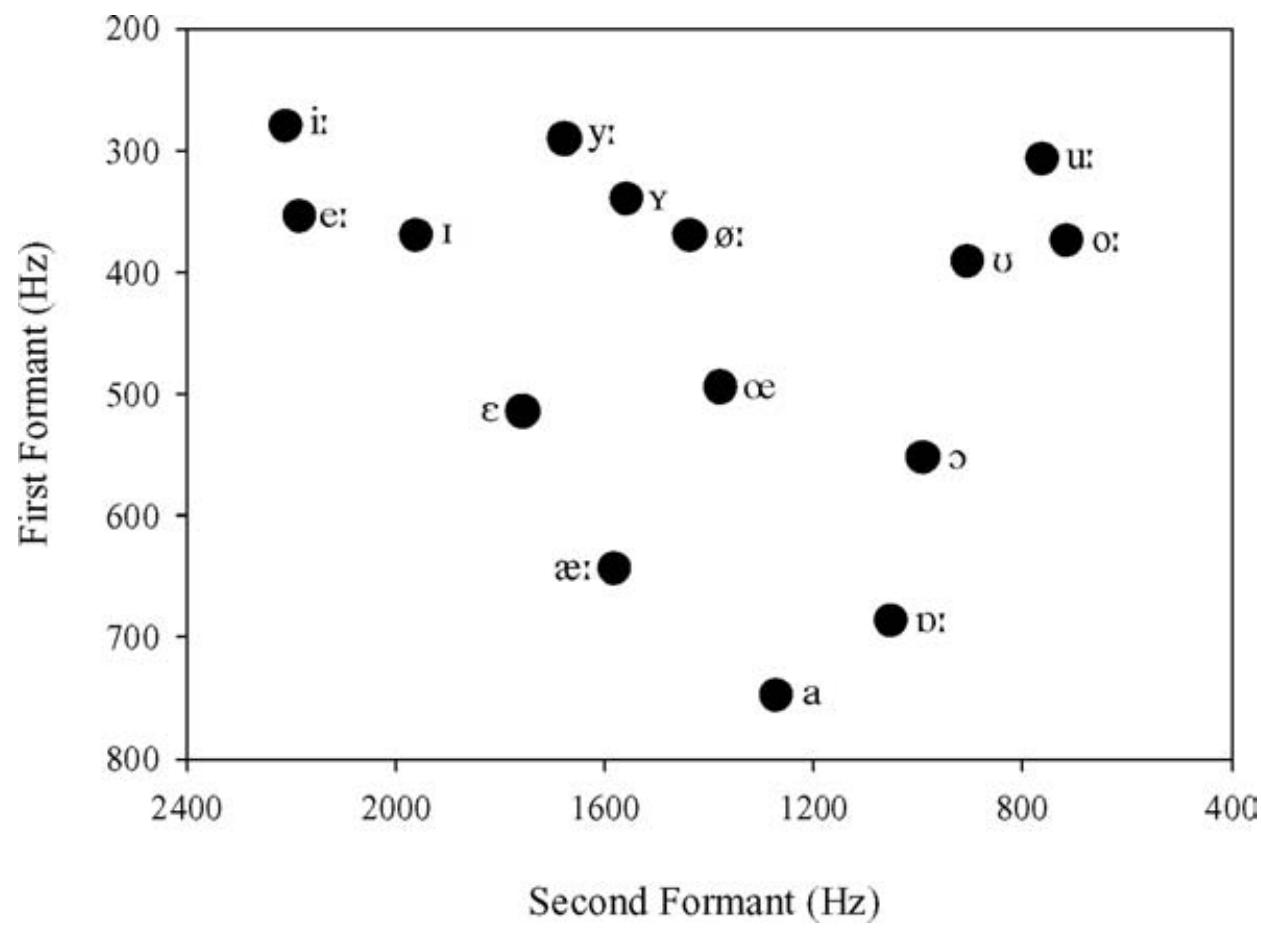

Figure 1 Location of the 15 stressed monophthongs of Fering (produced in /hVt/ syllables) in the F1/F2 vowel space. Each dot represents the mean values of the center F1 and F2 frequencies of 20 tokens of each /hVt/ syllable.

\section{Results}

\subsection{Spectral characteristics of Fering vowels}

\subsubsection{Center formant frequencies in /hVt/ syllables}

Figure 1 presents the mean values of the center F1 and F2 frequencies of 20 tokens each (10 talkers $\times 2$ repetitions) of the 15 stressed monophthongs of Fering produced in $/ \mathrm{hVt} /$ syllables. It was not possible to elicit/æ:/ (orthographically $\langle a ̈ a ̈\rangle)$ in the $/ \mathrm{hVt} /$ context, probably because of interference from the literary language Standard German, in which $\langle a ̈\rangle$ stands for /e/ or $/ \varepsilon /$. Acoustic measurements for this vowel were made from the one token of dä̈rr 'dare', which each speaker produced for the consonant word list.

Figure 1 suggests that the symbols used in the literature for the monophthongs of Fering correspond quite well to the acoustic quality of these vowels except for the lowest front vowel. This vowel has a much higher F1 frequency (and a lower F2 frequency) than the symbol / $/$ / would suggest. It should therefore not be transcribed as / $\varepsilon: /$ but as $/ æ: /$.

As in other languages with large vowel inventories (e.g. German and Danish, see Strange \& Bohn 1998, Steinlen 2002), the monophthongs of Fering are not evenly distributed in the acoustic vowel space. The upper portion of the vowel space is densely populated: 9 of the 15 vowels have mean F1 frequencies ranging from $390 \mathrm{~Hz}$ to $280 \mathrm{~Hz}$, whereas the mid and lower portion of the acoustic vowel space is less densely packed with 6 vowels ranging in F1 frequency from $760 \mathrm{~Hz}$ to $480 \mathrm{~Hz}$. Interestingly, the upper portion of the vowel space is also densely packed in Danish and North German; consider the spacing of $/ \mathrm{i}(\mathrm{:}) /-/ \mathrm{e}(\mathrm{:}) /$ and $/ \mathrm{u}(\mathrm{i}) /-/ \mathrm{o}(\mathrm{:}) /$ in the F1/F2 plots of figure 4 (below). Additional comparative phonetic 
Table 2 Percentage change in formant frequencies over the middle half of citation-form /hVt/ syllables.

\begin{tabular}{|c|c|c|}
\hline Vowel & F1 change & F2 change \\
\hline /ii:/ & $-1.4 \%$ & $-1.3 \%$ \\
\hline$/ \mathrm{I} /$ & -1.9 & -1.9 \\
\hline /e:/ & 4.2 & 1.6 \\
\hline$|\varepsilon|$ & 0.9 & -2.2 \\
\hline /a/ & -4.0 & 6.7 \\
\hline /y:/ & -2.8 & 3.1 \\
\hline$/ \mathrm{Y} /$ & 2.9 & 0.5 \\
\hline$/ \phi: /$ & -2.5 & 2.3 \\
\hline /œ/ & 0.5 & -0.8 \\
\hline /u:/ & -3.4 & 9.0 \\
\hline$/ v /$ & -3.4 & 12.5 \\
\hline /o:/ & -1.0 & 4.6 \\
\hline $10 /$ & 3.5 & 16.9 \\
\hline$/ \mathrm{D}: /$ & -3.9 & 5.3 \\
\hline
\end{tabular}

studies are needed to determine whether the uneven distribution of vowel in the vowels space is a general feature of languages with large vowel inventories, or whether we are dealing with a Sprachbund phenomenon of Fering, North German, and Danish, which are spoken in neighboring and overlapping geographical areas.

Languages with large vowel inventories differ with respect to the means that are used to keep vowel categories distinct (e.g. temporal contrasts with distinct sets of long vs. short vowels, distinct patterns of diphthongization (Vowel Inherent Spectral Change, or VISC), tense-lax contrasts with distinct patterns of onglides and offglides, see Andruski \& Nearey 1992, Strange \& Bohn 1998, Steinlen 2002). The present study examined the extent to which Fering employs temporal contrasts (see 3.2 section below) and VISC to enhance the distinctness of vowel categories.

\subsubsection{Vowel inherent spectral change (VISC)}

VISC was quantified by computing and transforming into a percentage score for each $/ \mathrm{hVt} /$ token changes in F1 and F2 frequencies from a point $25 \%$ into the vocalic duration to the $75 \%$ point. Table 2 shows the differences (including the sign), which were averaged over the 20 instances of each vowel. (VISC for the /æ:/ vowel was not computed because /æ:/ could not be elicited in the $/ \mathrm{hVt} /$ frame.)

Table 2 indicates that F1 movement through the middle half of all vowels in $/ \mathrm{hVt} /$ syllables was slight. F2 movement through the middle half was also slight for all but three vowels in which the change was close to or greater than $10 \%$ (which is the figure used by Andruski \& Nearey (1992) to characterize significant VISC in Canadian English vowels): /u/ (9.0\%), / / $/$ $(12.5 \%)$, and $/ \mathrm{J} /(16.9 \%)$. Inspection of formant trajectories suggested that these increases in F2 could be attributed to the fact that the $75 \%$ temporal point in these vowels was located in the final transitional portion of the $/ \mathrm{hVt}$ / syllables with $\mathrm{F} 2$ values converging on a value for /t/ of about $1500 \mathrm{~Hz}$.

\subsubsection{Diphthongs and triphthongs}

Figure 2 presents the trajectories of the 7 diphthongs of Fering. The trajectories are plotted by connecting F1/F2 values at the $25 \%$ temporal point (start of line) with the $50 \%$ temporal point (marked by a filled circle) and the $75 \%$ temporal point (marked by an arrowhead). 


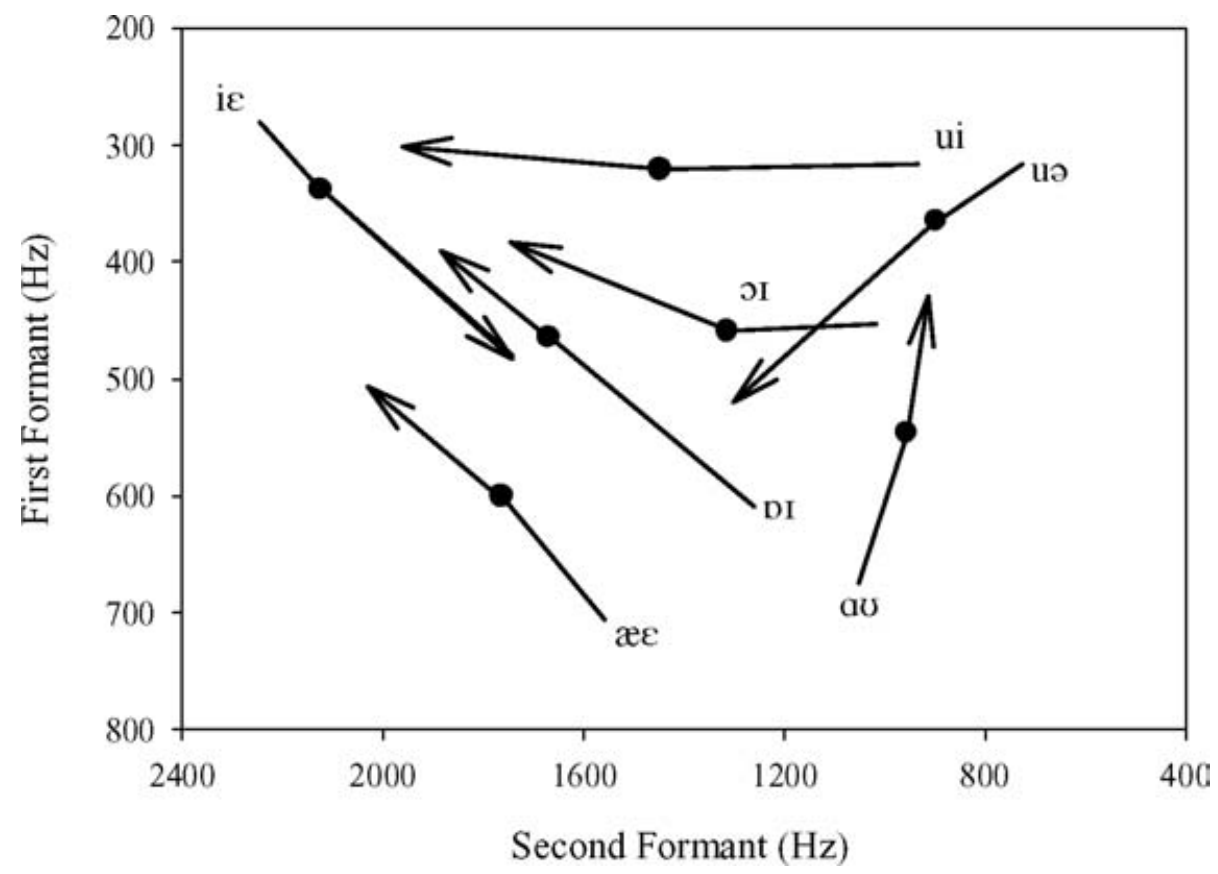

Figure 2 Trajectories of the Fering diphthongs in the F1/F2 vowel space.

Figure 2 suggests that the transcription of the Fering diphthongs as /عi/, /ui/, /au/, /ia/, /ua/, /pi/, / $₫ \mathrm{i} /$ (Walker \& Wilts 2001) is not closely related to the phonetic realization by the talker group in the present study. The acoustic analyses suggest that, respectively, the following phonetic transcriptions for the diphthongs of Fering: [æe], [ui], [av], [ic], [uə], [pr], [วr].

Comparison of figure 2 with table 2 suggests that, as far as inherent formant dynamics are concerned, the vowel inventory of Fering is strictly dichotomous: monophthongs are truly monophthongal, showing no VISC, whereas diphthongs are characterized by large formant dynamics with trajectories which cover approximately one half (or more) of the F1 and/or F2 dimension.

For a comprehensive phonetic documentation of Fering, an attempt was also made to record the three triphthongs listed in descriptions of Fering (see table 1). This was done irrespective of the morphological status of the triphthongs. It appears that /auə/ and / $\mathrm{pI} /$ are bimorphemic and possibly also bisyllabic, with a boundary before schwa (which is part of the /at/ participle suffix). Informal auditory evaluations of records from Fering speakers who were born in the 19th century suggest that /uai/, which does not straddle morpheme boundaries, was monosyllabic.

The trajectories of the triphthongs of Fering that could be recorded are shown in figure 3 . The trajectories are plotted by connecting F1/F2 values at the $20 \%$ temporal point (start of line) with the $40 \%$ and the $60 \%$ temporal points (filled circles) and with the $80 \%$ temporal point (marked by an arrowhead). The triphthong transcribed as /uai/ and listed as part of the vowel inventory of Fering in Sjölin et al. (1985) and Walker \& Wilts (2001) could not be elicited from the talkers in the present study. In the real words that were used in attempts to cue the production of /uai/, all talkers produced the diphthong/ui/. (The real words were spuai '(to) soothsay', gluai '(to) glare', fluai '(to) skin', tuai '(to) thaw'.) This suggests that /uai/ has merged with /ui/ in the oldest generation of male Fering speakers. Comparison with 


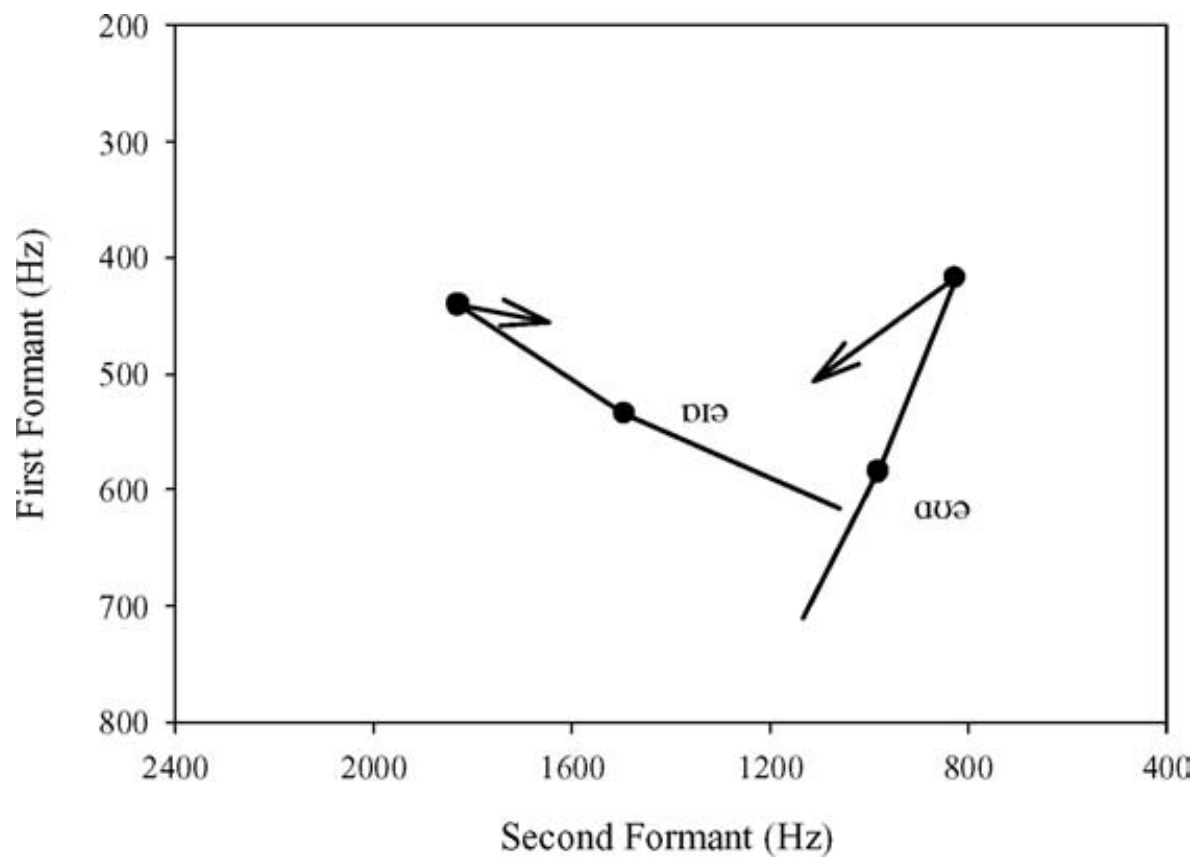

Figure 3 Trajectories of the Fering triphthongs in the F1/F2 vowel space (see text).

figure 2 suggest that the triphthongs that have been transcribed as /auə/ and /prə/ (Sjölin et al. 1985) are realized as the diphthongs [av] and [DI] plus a schwa offglide. It appears that this offglide truncates the trajectory for /piə/ so that its phonetic quality is [peə].

\subsubsection{Effect of consonantal context on center formant frequencies}

A recent study (Steinlen 2002), which compared the effect of consonant-vowel coarticulation on the acoustic differentiation of vowel categories in Southern British English, North German, and Danish, suggests that the degree to which vowels are coarticulated with flanking consonants is inversely related to the size of the vowel inventory. Steinlen (2002) used the size of the area covered by vowels in the F1/F2 space as an index of the acoustic differentiation of the vowel inventory. Specifically, Steinlen reported that the reduction of the area covered by Southern British English vowels (with 11 stressed monophthongs) in /dVt/ syllables was large compared to vowels produced in $/ \mathrm{hVt} /$ syllables, that this reduction was less for North German vowels (14 stressed monophthongs), and that Danish vowels (20 stressed monophthongs) were least coarticulated with only a minimal reduction of the vowel area for vowels produced in $/ \mathrm{dVt} /$ as opposed to /hVt/ syllables (see also Steinlen \& Bohn 1999).

Figure 4 shows the F1/F2 vowel spaces (defined by all but the front rounded and/or central vowels) for vowels produced in citation-form $/ \mathrm{hVt} / \mathrm{vs}$. $/ \mathrm{dVt} /$ contexts for Southern British English (top left), North German (top right), Fering (bottom left), and Danish (bottom right). The data from these four languages were recorded and analyzed in much the same way; each data point in figure 4 represents the mean value of at least 20 vowel tokens produced by 10 male speakers each. Visual inspection of these figures suggests that the degree of vowel area reduction for the Fering /dVt/ vowels is less than for the North German and Southern British English vowels, and that it is similar to the small coarticulatory effects observed for Danish, thus providing additional support for Steinlen's hypothesis. 
Southern British English

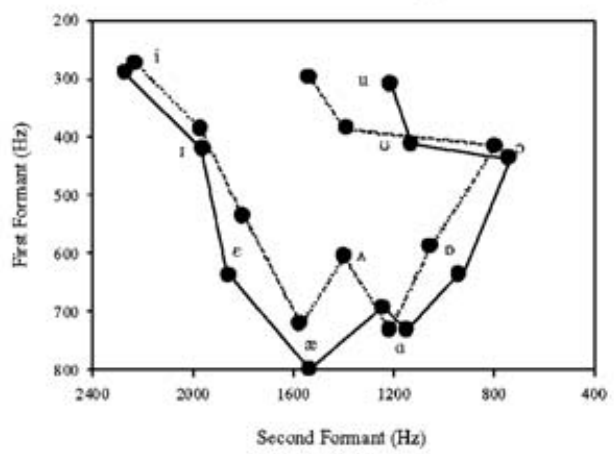

Fering

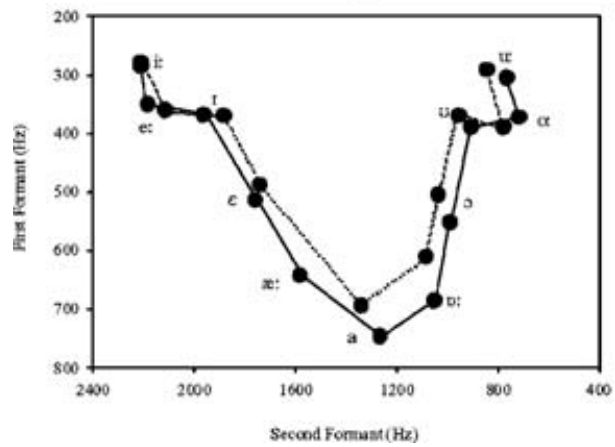

North German

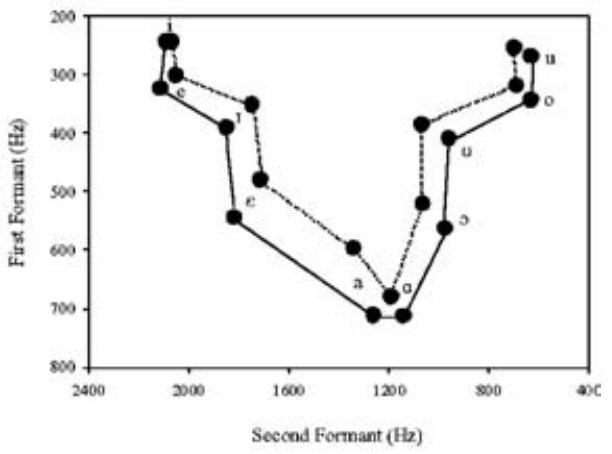

Danish

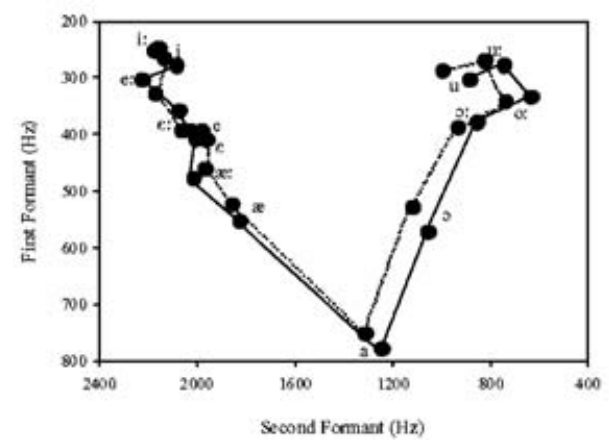

Figure 4 F1/F2 vowel spaces for vowels produced in an /hVt/ ( ) and a /dVt/ ( . . . ) context or four languages differing in vowel inventory size. (Data for English, German, and Danish from Steinlen 2002).

To further test the hypothesis that the degree of formant undershoot, resulting in vowel area reduction, is inversely related to the size of the vowel inventory, vowel area reduction for each of the four languages was quantified by computing the differences in center F1 and F2 formant frequencies for each vowel produced in the $/ \mathrm{hVt} / \mathrm{vs}$. $/ \mathrm{dVt} /$ context.

Figure 5 shows the mean displacements in F1 and F2 formant frequencies for the vowels that define the vowel area in Southern British English, North German, Fering, and Danish (i.e. all but the front rounded and central vowels), and relates these displacements to the size of the vowel inventories. Figure 5 suggests that the data from Fering are consistent with the hypothesis that there exists an inverse relationship between vowel inventory size and vowel area reduction due to coarticulatory effects on vowel formant frequencies.

However, the data from Fering also suggest that this is a nonlinear relationship. On the one hand, the coarticulatory effects in Fering are considerably less than in North German even though the size of the Fering inventory (15) differs by just one category from North German (14). On the other hand, the coarticulatory effects in Danish and in Fering are of a similar magnitude even though the two languages differ considerably in vowel inventory size (Fering: 15, Danish: 20). (Note, however, that the number of spectrally different vowel categories for Danish may be inflated as many of the Danish high front vowels can be grouped as long/short pairs with large temporal and minimal spectral differences.)

Clearly, more research is needed to examine in more detail the relationship between vowel inventory size and the magnitude of coarticulatory effects on the spectral properties 


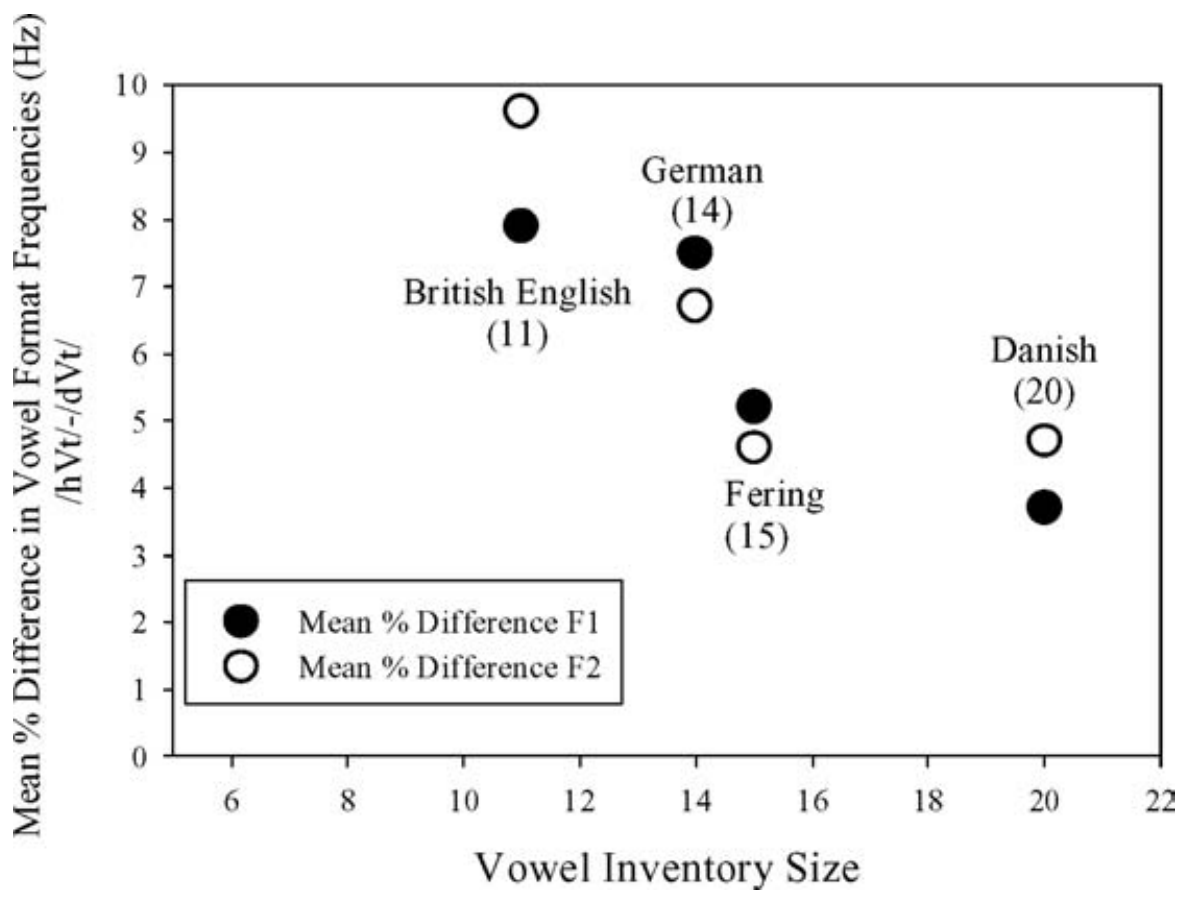

Figure 5 Coarticulatory effects on vowel formant frequencies as a function of vowel inventory size (stressed monophthongs).

of vowels, especially involving languages with vowel inventories that differ in size from the ones reported here.

\subsection{Temporal characteristics of Fering vowels}

\subsubsection{Vowel duration in citation form syllables}

Figure 6 presents the mean durations of Fering vowels produced in $/ \mathrm{hVt} /$ citation form syllables. The /æ:/ vowel is not included because it could not be elicited in the $/ \mathrm{hVt} / \mathrm{context}$. The monophthongs are grouped to reflect the traditional long/short distinction as used in Fering orthography with geminate letters for the long member of a pair, and a single letter for the short member, e.g. saat - sat 'set - sit'.

The mean duration values displayed in figure 6 suggest that the acoustic data support the traditional grouping of Fering monophthongs into long/short vowel pairs, and that Fering uses duration (rather than VISC, see table 2 above) to enhance the acoustic distinctness of monophthongs in its relatively large vowel inventory.

However, comparison of the duration data in figure 6 with the spectral data in figure 1 above indicates that Fering does not employ duration in precisely the fashion as suggested by Fering orthography, that is, to contrast $/ \mathrm{i}: /-/ \mathrm{I} /, / \mathrm{e}: /-/ \varepsilon /, / \mathrm{p}: /-/ \mathrm{a} /, / \mathrm{y}: /-/ \mathrm{y} /, / \phi: /-/ \propto /, / \mathrm{u} / /-/ \mathrm{v} /$, and /o:/ $/ \mathrm{o} /$. (The unambiguous orthographical representations of these vowels are, respectively, $\langle i i\rangle-\langle i\rangle,\langle e e\rangle-\langle e\rangle,\langle a a\rangle-\langle a\rangle,\langle\ddot{u} u ̈\rangle-\langle\ddot{u}\rangle,\langle\ddot{o} 0 \ddot{\rangle}-\langle\ddot{o}\rangle,\langle u u\rangle-\langle u\rangle,\langle o o\rangle-\langle o\rangle$.

Figure 1 above shows that the vowels in each pair (except for $/ \mathrm{p}: /-/ \mathrm{a} /$ and $/ \mathrm{y}: /-/ \mathrm{Y} /$ ) are not close neighbors in the F1/F2 space. For instance, the vowel that is spectrally closest to /i:/ is /e: $/($ not $/ \mathrm{I} /$ ), the vowel that is spectrally closest to $/ \mathrm{u}: /$ is $/ \mathrm{o}: /($ not $/ \mathrm{v} /)$, and both $/ \mathrm{e}: / / \varepsilon /$ and /o:/ / / / are far apart in the F1/F2 space. Also, the vowels labeled 'long' in figure 6 seem to 


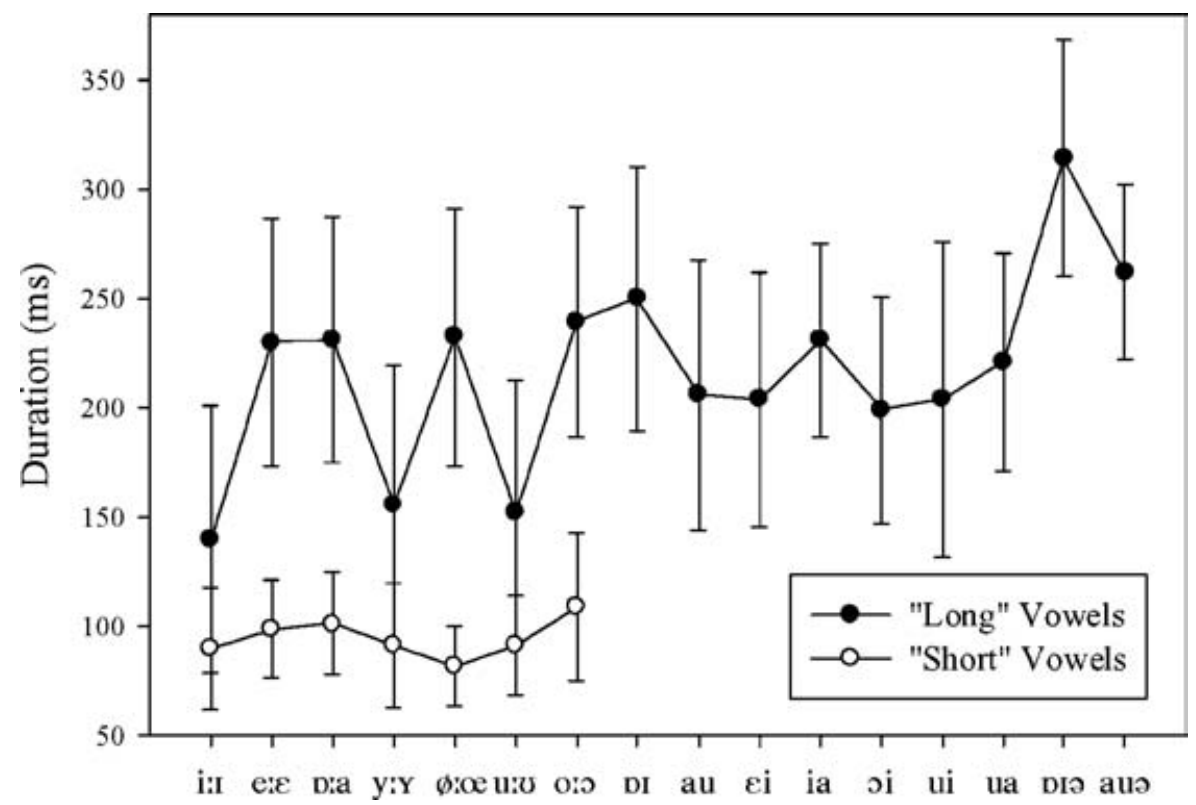

Figure 6 Duration of Fering vowels (citation form /hVt/ context). Error bars indicate $+/-1 \mathrm{SD}$.

consist of two groups: those with long mean durations of nearly $250 \mathrm{~ms}(/ \mathrm{e} / \mathrm{,} / \mathrm{bz} /, / \phi \mathrm{s} /, / \mathrm{oz} /)$, and those with medium durations of ca. $150 \mathrm{~ms}(/ \mathrm{i} / \mathrm{l}, / \mathrm{y}: /, / \mathrm{u} /)$ ).

Concerning the fact that most of the nominally long/short vowel pairs are widely separated in the F1/F2 space, it appears that Fering orthography and with it the traditional grouping of Fering vowels into long/short pairs is historically adequate, but does not reflect the present shape of the Fering vowel system. The short vowels of Fering have served as an extreme example of the universal tendency of short vowel lowering (Labov 1994). For instance, Fering /a/ corresponds to /I/ or short /i/ in other Germanic languages as in Fering fask 'fish' and sark 'church'. Thus, the large spectral separation of vowels which previously formed long/short vowel pairs is due to diachronic vowel shifts: the lowering of short vowels and perhaps also the raising of some of the long vowels.

The nominally long vowels are realized either as vowels of medium duration (/i:/, /y:/, /u:/) or of long duration (/e:/, /p:/,/ $/$ :/, /o:/). The medium-duration vowels are located close to long-duration vowels in the F1/F2 space. The comparatively short duration of the nominally 'long' Fering vowels /i:/, /y:/, /u:/ could be interpreted as a language-specific exploitation (and enhancement) of the universal inverse relationship between vowel height and duration (Meyer 1904, Lehiste 1970): The naturally relatively short high vowels /is/, /y:/, /u:/ have especially short duration in Fering to make them more distinct from the spectrally neighboring vowels /e:/, / $\phi: /, / 0: /$. Thus, the vowel duration data from Fering present supporting evidence for the view that details of phonetic implementation may be language specific and must therefore be part of the grammar of each language (e.g. Keating 1984, Pierrehumbert 1990). In addition, the present data suggest a functional (i.e. contrast-enhancing) motivation for the implementation of temporal vowel contrasts in Fering.

\subsubsection{Speaking rate effects on vowel duration}

The present study examined speaking rate effects on vowel duration and on the implementation of duration contrasts using data from the production of real Fering words in citation form 


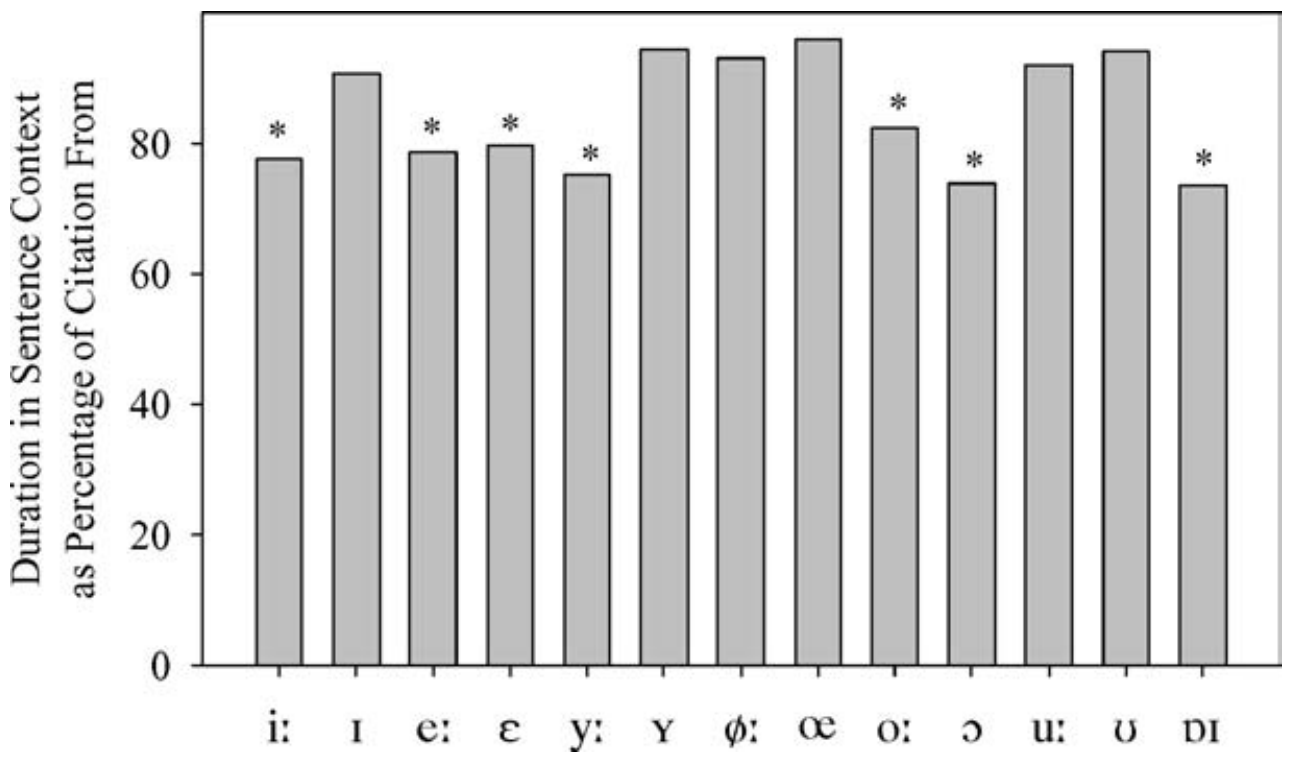

Figure 7 Effect of speaking rate on vowel duration (An asterisk indicates a difference between citation form and sentence context duration that was significant at $p<.05)$.

and in the sentence context $I k$ sai $X$ tu di 'I say X to you'. The results reported here concern speaking rate effects on the vowels $/ \mathrm{i}: /, / \mathrm{I} /, / \mathrm{e}: /, / \varepsilon /, / \mathrm{y}: /, / \mathrm{Y} /, / \phi: /, / \infty \mathrm{c} /, / \mathrm{o}: /, / \mathrm{\rho} /, / \mathrm{pI} /$, measured from the maximally 20 tokens each ( 10 speakers $\times 2$ repetitions) as produced in the words kiimen 'gill', kiming 'horizon', beed 'prayer', bed 'bite', üüs 'as', üs 'us', sköödel 'latch', sköde 'shake', poot 'graft', pot 'pot', laid 'lightning'.

Figure 7 shows that all 11 vowels were produced with shorter duration in sentence context as compared to citation form, but separate t-tests revealed that the shortening effect of the faster speaking rate in sentence context was significant for only 7 of the 11 vowels examined (i.e. /i:/, /e:/, /ع/, /y:/, /o:/, /o/, /pi/).

The present data are inconclusive as to why the duration of some vowels is significantly affected by speaking rate, whereas other vowels seem to be less compressible. The pattern observed here is unrelated to factors that have been suggested in the literature, e.g. the long/short distinction, vowel height, the voicing of the following consonant, syllable structure (open or closed), or the number of syllables of the word in which the vowel was produced (e.g. Port 1981, Gopal 1996).

Figure 8 shows the effect of speaking rate the on the temporal contrasts for the subset of vowels which showed a significant effect of speaking rate.

The data presented in figure 8 suggest that speaking rate does not systematically affect the proportional temporal contrasts between long and short vowels in Fering. For the three long/short vowel pairs for which data were available, a difference in speaking rate did not result in a systematic increase or decrease of the duration ratios. The fact that Fering speakers maintain duration contrasts independently of speaking rate suggests that vowel length is a more important feature in Fering than in e.g. North German (with tense/lax vowel pairs), in which the duration ratios for tense/lax vowel pairs are significantly smaller for vowels produced in sentence context as opposed to citation from (Strange \& Bohn 1998). 


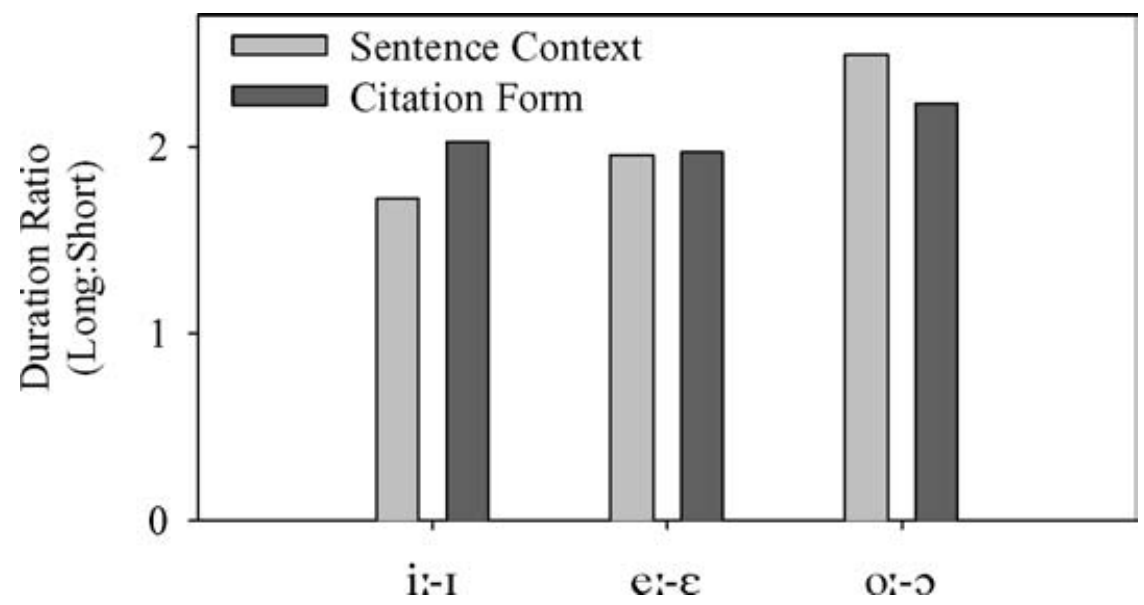

Figure 8 Effect of speaking rate on temporal differentiation of vowel contrasts.

\section{Conclusion and outlook}

Acoustic documentation of the sounds of the endangered West Germanic language Fering has been used to describe the spectral and temporal characteristics of Fering vowels. The monophthongs of Fering are not evenly distributed in the F1/F2 space; the upper portion of the vowel space is more densely populated than the lower portion. Vowel inherent spectral change is restricted to the diphthongs and triphthongs of Fering, the monophthongs of Fering exhibit no inherent formant dynamics. The small coarticulatory effects of consonantal context on the center formant frequencies of Fering vowels are consistent with the hypothesis of an inverse relationship between vowel inventory size and formant undershoot due to consonant-vowel coarticulation. The traditional classification of Fering vowels as long or short is supported by acoustic measurements, but the use of duration to keep spectrally similar vowels distinct is more complex than implied by the orthography of Fering. Speaking rate affects the duration of some but not all Fering vowels significantly. The duration ratios of those long/short vowel pairs whose members show speaking rate effects seem to be immune to changes in speaking rate.

The results of the present study raise a number of interesting questions which should be addressed in future research. With respect to general phonetics, perhaps the most interesting question concerns further exploration of the relationship between vowel inventory size and coarticulatory effects on vowels. Also of interest is the generality of the finding that the upper, as opposed to the lower, portion of the vowel space is relatively crowded in Fering and in neighboring Germanic languages. With respect to historical linguistics, sociolinguistics, and multilingualism, it would be interesting to compare the present findings to future studies for changes in the vowel system of Fering in apparent time and/or real time, and to relate these changes to cross-language influences of Fering and its primary contact languages.

\section{Acknowledgements}

Data collection and analysis were supported by a grant from the Ferring Foundation. Special thanks to Ocke Danklef Bohn for help in recruiting talkers, to Christa Bohn and Eva Paulsen for their hospitality, to Volkert Faltings and Reinhard Jannen for help in generating the reading lists, to Rikke BundgaardNielsen for help in segmentation and acoustic analysis, and to Karen Ebert and Peter Ladefoged for 
encouragement and comments on a previous version of this paper. A selection of Fering audio files can be accessed at the Aarhus University web site http:/www.hum.au.dk/engelsk/engosb/fering.html

\section{References}

ANDRUSKI, J. E. \& NEAREY, T. M. (1992). On the sufficiency of compound target specification of isolated vowels and vowels in /bVb/ syllables. Journal of the Acoustical Society of America 91, 390-410.

ARFSTEN, R. (1965). Fering Wurdenbuk (weesdring). Bredstedt: Nordfriisk Instituut.

Århammar, N. (1968). Friesische Dialektologie. In Schmitt, L. E. (ed.), Germanische Dialektologie: Festschrift für Walter Mitzka zum 80. Geburtstag, 264-317. Wiesbaden: Franz Steiner.

GopaL, H. S. (1996). Generalizability of current models of vowel duration. Phonetica 53, 1-32.

Labov, W. (1994). Principles of Linguistic Change, vol. 1: Internal Factors. Oxford: Blackwell.

LEHISTE, I. (1970). Suprasegmentals. Cambridge, MA: MIT Press.

KEATING, P. A. (1984). Phonetic and phonological representation of stop consonant voicing. Language 60, 286-319.

MeYER, E. A. (1904). Zur Vokaldauer im Deutschen. Nordiska Studier tillegnade Adolf Noreen, 347-356. Uppsala: K. W. Appelberg.

Pierrehumbert, J. B. (1990). Phonological and phonetic representation. Journal of Phonetics 18, 375 394.

PORT, R. F (1981). Linguistic timing factors in combination. Journal of the Acoustical Society of America 69, 262-274.

SJÖLIN, B., BRAREN, E. \& Wilts, O. (1985). Fering för Beganern. Kiel: Didactica Frisica 1.

STEINLEN, A. K. (2002). A cross-linguistic comparison of the effects of consonantal contexts on vowels produced by native and non-native speakers. Ph.D. thesis, English Department, Aarhus University.

StEINLEN, A. K. \& BoHn, O.-S. (1999). Acoustic studies comparing Danish vowels, British English vowels, and Danish-accented British English vowels. Journal of the Acoustical Society of America 105, 1097.

StRAnge, W. \& Bohn, O.-S. (1998). Dynamic specification of coarticulated German vowels: Perceptual and acoustical studies. Journal of the Acoustical Society of America 104, 488-504.

WAlKer, A. \& Wilts, O. (2001). Die nordfriesischen Mundarten. In Munske, H. H. (ed.), Handbuch des Friesischen/Handbook of Frisian Studies, 284-304. Tübingen: Max Niemeyer.

Wilts, O., Braren, E. \& HinRIChSEN, N. (1986). Wurdenbuk för Feer an Oomram. Norddorf: Jens Quedens. 